\section{VITAMIN D DEFICIENCY}

\section{More evidence is needed before general supplementation}

Holick is right to highlight the high prevalence of vitamin $D$ insufficiency in many groups of people living at higher latitudes. ${ }^{1}$ However, the evidence base to support general supplementation, including aggressive fortification, does not currently exist.

An impressive array of observational data suggests that low vitamin D concentrations are associated with a wide variety of diseases, including diabetes, cardiovascular disease, and cancer. This does not necessarily mean that intervention with vitamin D supplementation will improve health outcomes-witness the problems of hormone replacement therapy despite encouraging observational data, not to mention the lack of effect and possible harms surrounding vitamins $A, E$, and $\beta$ carotene supplementation. ${ }^{2}$

Although traditional vitamin D toxicity may be unlikely even with relatively large doses of vitamin $D$, we cannot be sure that long term vitamin $D$ supplementation does not in fact cause some harms-and the case for benefits is far from proved. The recent women's health initiative study of low dose calcium and vitamin D supplementation showed no change in risk of colorectal cancer, diabetes, stroke, or cardiovascular disease, but the regimen did produce an increase in the number of renal stones. ${ }^{3}$ Recent observational data from the Framingham study suggests that the risk of cardiovascular events may be lowest at 25 - hydroxy vitamin D levels of around $60 \mathrm{nmol} / \mathrm{l}$, possibly increasing slowly at levels above this. ${ }^{4}$

The only way to resolve these uncertainties is to conduct large scale randomised controlled trials comparing different doses of vitamin $D$ with placebo. Only then will we be able to weigh up the balance of benefit and risk, decide which groups of people would gain net benefit, and thus make safe and sensible recommendations on vitamin $D$ supplementation.

Miles D Witham clinician scientist, ageing and health, University of Dundee, Ninewells Hospital, Dundee DD19SY Competing interests: MDW has received grant income from the Scottish government, Chest Heart and Stroke Scotland, Diabetes UK, and Heart Research UK to investigate the effects of vitamin D on the cardiovascular system.

1 Holick MF. Deficiency of sunlight and vitamin D. BMJ 2008;336:1318-9. (14 June.)

2 Bjelakovic G, Nikolova D, Gluud LL, Simonetti RG, Gluud C. Antioxidant supplements for prevention of mortality in healthy participants and patients with various diseases. Cochrane Database Syst Rev 2008;(2):CD007176.

3 Hsia J, Heiss G, Ren H, Allison M, Dolan NC, Greenland $P$, et al. 2007 Women's Health Initiative. Calcium/ vitamin D supplementation and cardiovascular events. Circulation 2007;115:846-54.

4 Wang TJ, Pencina MJ, Booth SL, Jacques PF, Ingelsson $\mathrm{E}$, Lanier K, et al. Vitamin D deficiency and risk of cardiovascular disease. Circulation. 2008;117:503-11.

\section{Vitamin D deficiency is widespread in Scotland}

I agree with Holick ${ }^{1}$ and Sievenpiper et $\mathrm{al}^{2}$ about the urgent need to highlight the neglected subject of vitamin D deficiency in the United Kingdom. We have found in our general practice in Edinburgh a (to us) surprisingly high prevalence of gross vitamin D deficiency. The deficiency affects not only our South Asian patients but also a considerable number of those with white skin colour.

Between 2005 and 2007, blood samples were taken from 99 patients aged 15-85. We included patients suspected of having a possible vitamin $D$ deficiency: patients of South Asian origin or other ethnic minorities, patients with vague musculoskeletal symptoms or overweight, patients taking antiepileptic drugs, patients using sunscreen or make up, housebound patients, and patients with little exposure to sunlight. The figure shows our as yet unpublished results.

According to the definitions of most vitamin $\mathrm{D}$ researchers, insufficient vitamin D concentrations are those below $75 \mathrm{nmol} / \mathrm{l}$. In our sample only $2 \%$ had a sufficient vitamin D concentration. Measurements below $25 \mathrm{nmol} / \mathrm{l}$ are defined as severe deficiency; in our sample, the proportion was $47 \%$.

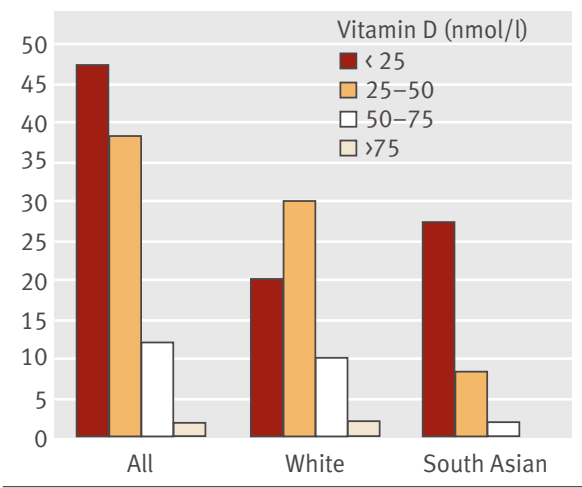

Vitamin D concentrations in 99 patients aged 15-85 with suspected vitamin $D$ deficiency by ethnic group
Hyppoenen and Power reported similar figures for Scotland. ${ }^{3}$

Helga M Rhein general practitioner, Sighthill Health Centre, Edinburgh EH11 4AU helga.rhein@blueyonder.co.uk

Competing interests: None declared.

1 Holick MF. Deficiency of sunlight and vitamin D. BMJ 2008;336:1318-9. (14 June.)

2 Sievenpiper JL, McIntyre EA, Verrill M, Quinton R, Pearce SHS. Unrecognised severe vitamin D deficiency. BMJ 2008;336:1371-4. (14 June.)

3 Hyppoenen E, Power C. Hypovitaminosis D in British adults at age $45 \mathrm{y}$ : study of dietary and lifestyle predictors. AmJ Clin Nutr 2007;85:860-8.

\section{MISSED OPPORTUNITIES}

\section{Undiagnosed HIV infection in patients with viral hepatitis}

A third of HIV infected people in the UK are unaware of their infection. ${ }^{1}$ Many repeatedly access medical care but are not diagnosed until much later in their disease course. ${ }^{12}$ The chief medical officer recently called on doctors to improve recognition of undiagnosed HIV infection nationwide. One strategy is the adoption of routine opt-out HIV testing in settings where undiagnosed people may present. ${ }^{3}$ While patients' acceptance may not be an important barrier, ${ }^{4}$ uncertainties remain about the benefit of widespread routine testing, partly based on the assumption that clinical judgment can identify patients at risk of infection. To inform HIV testing strategies, data on the likely yield from changed testing policies are required. ${ }^{3}$ We show here that half of HIV infected patients attending a viral hepatitis referral unit that follows a clinician directed testing policy remain undiagnosed.

With ethics committee approval, we conducted a retrospective, anonymous HIV seroprevalence study among 268 adults with chronic viral hepatitis (C 56\%, B 34\%, B+C $3 \%)$ or abnormal liver function tests (7\%). Four (1.5\%; 95\% confidence interval 0.04\% to $2.82 \%$ ) tested HIV1 positive (one woman, three men, age 33-53). One patient was known to be HIV positive before referral. During the study period, 12 HIV clinician directed tests were done, which identified one further positive patient. Two $(0.75 \%)$ patients had undiagnosed HIV infection, both white males with hepatitis $C$ acquired through intravenous drug use or an undetermined route. Thus, HIV seroprevalence exceeded that in the general $(0.2 \%)$ and antenatal $(0.09 \%)$ population, while prevalence of undiagnosed infection was well above the 
suggested threshold $(0.05-0.1 \%)$ that makes routine testing cost effective. ${ }^{5}$

Some $30 \%$ of HIV infected individuals are also infected with hepatitis C, and $10 \%$ have chronic hepatitis B. Progression of liver disease is accelerated in co-infected patients. In addition, antivirals against hepatitis B can induce HIV drug resistance in undiagnosed persons. Whereas practice guidelines for HIV recommend routine hepatitis $B$ and $C$ testing, those for chronic viral hepatitis suggest selective HIV testing for individuals judged to be at risk. Our results indicate that clinical judgment is not sufficient to ensure that all persons at risk of HIV infection are identified. We recommend adoption of routine opt-out HIV testing in patients with chronic viral hepatitis.

Anna Maria Geretti consultant in virology

a.geretti@medsch.ucl.ac.uk

Sara Madge associate specialist in HIV medicine,

Marcus Posner medical student, Geoff Dusheiko professor

of hepatology, Michael Jacobs senior lecturer in infectious

diseases, Royal Free Hospital and Royal Free and University

College Medical School, London NW3 2QG

Competing interests: AMG is an elected member of the British HIV Association's executive committee.

1 UK Collaborative Group for HIV and STI Surveillance. Testing Times-HIV and other sexually transmitted infections in the United Kingdom: 2007. London: Health Protection Agency, Centre for Infections, 2007.

2 British HIV Association. 2005-6 Full results of mortality audit. http://www.bhiva.org/cms1192339.asp

3 Hamill M, Burgoine K, Farrell F, Hemelaar J, Patel G, Welchew DE, et al. Time to move towards opt-out testing for HIV in the UK. BMJ 2007;334:1352-4.

4 Haukoos JS, Hopkins E, Byyny BL. Patient acceptance of rapid HIV testing practices in an urban emergency department: Assessment of the 2006 CDC recommendations for HIV screening in health care settings. Ann Emerg Med 2008;51:303-9.

5 Branson BM, Handsfield HH, Lampe MA, Janssen RS, Taylor AW, Lyss SB, et al. Revised recommendations for HIV testing of adults, adolescents, and pregnant women in health-care settings. MMWR Recomm Rep 2006;55(RR-14):1-17.

\section{PROLAPSED INTERVERTEBRAL DISC}

\section{What if back surgery was a drug?}

I find it fascinating that surgical treatments and medical treatments are evaluated very differently in the literature and by ethics committees. ${ }^{1}$ Let's say you told a human research ethics committee (HREC) that you expected only a short to medium term reduction in radicular pain with no real improvement in disability or axial back pain for a drug treatment. You go on to say that treatment had a $70 \%$ chance of entrenching the axial back pain as permanent, a $5 \%$ chance of worsening the pain, $1 \%$ risk of permanent neurological damage, with lesser chances of major vessel damage or paraplegia, I wonder how many HRECs would approve it ? If you then presented a literature search that relied mainly on a 30 year old study with major design flaws and a couple of meta-analyses of poor data you could reasonably expect to be sent packing. By way of comparison, in Australia last year lumiracoxib was banned by the Therapeutic Goods Administration for causing fulminant hepatitis at a rate of one in 15000 , with two deaths out of an estimated 60000 patients who received it.

Without a standard battery of outcome measures which can be used in both surgical and non-surgical trials, and without sham surgical studies, which must measure pain related disability and psychological outcomes (since there is clear evidence that these influence overall disability in a major way) it is difficult to interpret the vast but mostly useless back pain literature.

Michael Vagg interventional pain physician, VMO Pain Management Unit, Barwon Health, Geelong, VIC 3220, Australia mickvagg@yahoo.com.au

Competing interests: None declared.

1 FairbankJ. Prolapsed intervertebral disc. BMJ 2008;336:1317-8. (14 June.)

\section{BLOOD PRESSURE IN CHILDREN}

\section{Is screening for hypertension in children essential?}

Advocating routine screening for high arterial pressure in children, Bird and Michie suggest that healthcare workers be reminded of how simple it is to measure blood pressure in children. ${ }^{1} \mathrm{My}$ wife and I measured arterial pressures in all newborns in our total primary care population (all ages) of around 1700 , with follow-up readings monthly in the first year, and annually thereafter to age 11 , from 1977 to $1987 .{ }^{2}$ Our original intention was to relate our findings to data we already had on all these children's parents, ${ }^{3}$ but we never published our findings.

We found these measurements extremely difficult, and not because of crying babies (an elementary obstacle we soon overcame). For children, even of school age, accurate estimates of mean arterial pressure are even more difficult than in adults, because measurements are so unstable. In schoolchildren we found several with very high systolic pressures when measured in the school clinic (over $160 \mathrm{~mm} \mathrm{Hg}$ in some cases). When repeated by the same observer in my office, where these children were accustomed to examinations of all kinds, all these high pressures fell within normal limits.

This experience made me extremely mistrustful of authorities which advocate screening for "essential" hypertension in childhood. For who is it essential? Apart from necessary and useful epidemiological research, the geographical distribution of such screening as a routine procedure suggests that this may concern the interests of medical trade rather than those of medical science or health gain. The time to start screening is in young adults, where we found a usefully high prevalence under 40 , possibly typical of high morbidity industrial and post-industrial populations. $^{4}$

Bird and Michie start from their experience in hospital emergency departments. I am surprised that despite this they virtually ignore the really important failure of most workers in primary care to measure arterial pressure at all, let alone accurately with appropriate cuffs, in children where this is urgently indicated by other evidence of renal disorders, abdominal masses, proteinuria, headache, visual disturbances, or diminished femoral pulses. Diagnosis for these children is still all too often delayed until there is already irreversible organ damage, sometimes catastrophic, ending in just such emergency departments. Clinical alertness will not be improved by adding yet another poorly performed measurement to unimaginative, thoughtless routines, searching for a clinical problem which for practical purposes does not exist.

Julian Tudor Hart honorary research fellow, University of Wales Swansea Medical School, Swansea SA32HH julian@tudorhart.freeserve.co.uk

Competing interests: None declared.

1 Bird C, Michie C. Measuring blood pressure in children. BMJ 2008;336:1321. (14 June.)

2 Hart JT. High blood pressure in childhood and adolescence, and the origins of adult disease in childhood. In, Hart JT. Hypertension: community control of high blood pressure. 3rd ed. Oxford: Radcliffe Medical Press, 1993.

3 Hart JT. The marriage of primary care and epidemiology: continuous anticipatory care of whole populations in a state medical service (Milroy lecture). I R Coll Physicians (London) 1974:8:299-314.

4 Hart JT, Edwards C, Haines AP, Hart M, Jones J, Jones $M$,et al. Screen detected high blood pressure under 40: a general practice population followed up for 21 years. BMJ 1993;306:437-40.

ASPECTS OF SUMMARY CARE RECORDS

\section{Let's put worry about computer security into perspective}

Greenhalgh et al found that patients were particularly concerned about computer security and inappropriate access for the proposed centrally stored medical record, ${ }^{1}$ a tenth citing such concerns as justification to reject or at least remain undecided on the benefit of a Healthspace account.

Electronically stored patient information remains topical in relation to security ${ }^{2} 3$ and recent high profile breaches of security. ${ }^{4}$ However, these concerns must be viewed in the context of current arrangements. Human links in the patient record chain are far more vulnerable 
to error, and we have been alarmed at the ease with which we have obtained confidential patient details by telephone.

Faced with incomplete demographic details in an audit, we attempted to complete gaps in addresses, contact numbers, and current treatments by telephoning patients' own GP surgeries. We contacted 45 different GP receptions for information on 51 patients, successfully obtaining patient addresses or telephone numbers, or both, for 50 of them. In over a third of phone conversations no information or verification was requested to obtain this information. In the one unsuccessful case the receptionist had asked for verification of our identity, which we were unable to provide over the telephone.

We greatly appreciate the ease with which GP receptionists assisted us, but such help is potentially open to abuse by anyone with a convincing medical story "calling from the hospital." Such a story easily overcomes natural safeguards; hacking into a Healthspace account would be considerably more difficult.

The current debate on the security of electronic medical records should perhaps re-focus on the current potential for breaches rather than conceptual ones in the future.

J E F Fitzgerald specialist trainee, general surgery edwardfitzgerald@doctors.org.uk

A Nikkar-Esfahani medical student, A A B Jamjoom medical student, K K Shah medical student, A G Acheson consultant colorectal surgeon, Nottingham University Hospitals NHS Trust, Nottingham NG7 2UH

Competing interests: None declared.

1 Greenhalgh T, Wood GW, Bratan T, Stramer K, Hinder S. Patients' attitudes to the summary care record and HealthSpace: qualitative study. BMJ 2008;336:1290-5. (7 June.)

2 McGilchrist M, Sullivan F, Kalra D. Assuring the confidentiality of shared electronic health records. $B M$ 2007;335:1223-4.

3 Chhanabhai P, Holt A. Consumers are ready to accept the transition to online and electronic records if they can be assured of the security measures. Med Gen Med 2007;9:8

4 Chivers T. Data loss crisis spreads to the NHS. Daily Telegraph www.telegraph.co.uk/news/main. jhtml?xml=/news/2007/12/23/ndata223.xml

\section{GP computerised summaries may not be accurate or complete}

The focus group in the study by Greenhalgh et al was concerned about the quality of data in the summary care record. ${ }^{1}$ Computerised medical summaries in primary care may not be accurate or complete mainly because of errors in transferring information from written medical records. When checking the computerised medical summaries of new patients against the written notes and letters, I have found a diagnosis coded and entered into the summary when the consultant's letter stated that the patient did not have this condition; a provisional diagnosis entered as a definite diagnosis, even when it was later excluded; the wrong Read code being used; an important diagnosis omitted from the summary; and misunderstanding of clinical information.

Medical records summarisers need to be well trained, ideally with a clinical background, and have enough time to do a thorough job. Quickly scanning through letters for diagnoses without reading the sentences leads to errors.

Mistakes can also be propagated when patients move to a new practice if the computerised medical summaries are simply copied. When computerised records become transferable between all practices the written notes will probably not even be looked at. Now is the time to check that this written information has been accurately transferred, particularly if the records are going to be used to build a central database.

Pamela J F Smith medical records summariser and former general practitioner, Stockport

pjfsmith1@aol.com

Competing interests: None declared.

1 Greenhalgh T, Wood GW, Bratan T, Stramer K, Hinder S. Patients' attitudes to the summary care record and HealthSpace: qualitative study. BMJ 2008;336:1290-5. (7 June.)

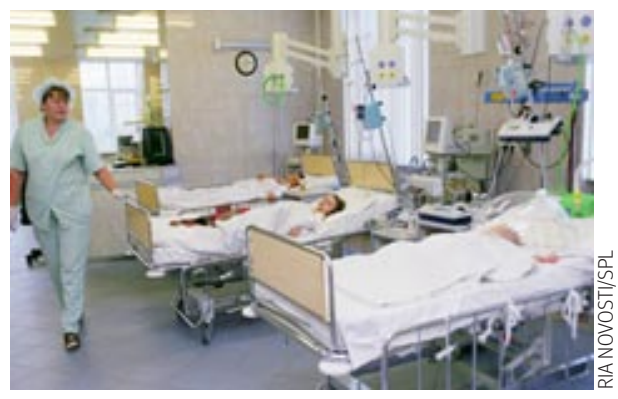

INVASIVE MENINGOCOCCAL DISEASE

\section{Cerebral perfusion in invasive meningococcal disease}

I am surprised that the SIGN guidelines (and therefore this summary of them ${ }^{1}$ ) make no mention of the importance of adequate cerebral perfusion in those with invasive meningococcal disease. Cerebral perfusion pressure is the difference between the mean arterial pressure (which is usually low from the associated hypotensive shock) and the intracranial pressure (which is often high as a result of meningeal inflammation and cerebral oedema).

Consequently, cerebral perfusion pressure takes a "double whammy," and the end result may be clinically significant cerebral ischaemia from profoundly inadequate cerebral perfusion, which is likely to worsen neurological outcomes.

The SIGN guidelines discuss the importance of early inotropic support, but fail to address the issues of raised intracranial pressure and the reduction in cerebral perfusion. If there are clinical or computed tomography scan signs of raised intracranial pressure, the use of osmotic agents such as mannitol should be actively considered and if necessary repeated.

Children and adults with severe invasive meningococcal disease often end up on the intensive care unit, where they may be sedated and ventilated while their cardiorespiratory status is optimised. In these circumstances, it is difficult to detect whether there have been any neurological changes or a drop in conscious level consequent to a raised intracranial pressure. A normal brain scan may not exclude this, and it may be difficult to detect. Surrogate methods of detecting poor cerebral perfusion such as jugular venous bulb oxygen saturation and the use of monitoring intracranial pressure may need to be considered.

Peter J Flegg consultant physician, Blackpool Victoria Hospital, Blackpool FY3 8NR dr.flegg@bfwh.nhs.uk Competing interests: None declared.

1 Theilen U, Wilson L, Wilson G, Beattie JO, Qureshi S, Simpson D; on behalf of the Guideline Development Group. Management of invasive meningococcal disease in children and young people: summary of SIGN guidelines. BMJ 2008;336:1367-70. (14 June.)

\section{BMJ IN “SMUG DOCS" STORM}

\section{Methinks the professor doth protest too much}

McManus seems to be attempting to distance himself from some unwise reactionary comments in an editorial to a rather good piece of work from Garlick and Brown. ${ }^{1-3}$ Perhaps his supporters should carefully look at what McManus actually said, ${ }^{3}$ as opposed to what he is saying he stated. He said "UK medical students tend to come from higher socioeconomic classes, perhaps not surprisingly, as social class correlates with intellectual ability."

What he and his supporters seem now to be saying is that social class correlates to performance at $A$ level, which is not what McManus said. I agree that A level performance correlates with social class as higher social classes tend to be able to afford private education and other educational support mechanisms. The logical extension of his comments is that intellectual ability correlates to financial wealth, as children from wealthier backgrounds can afford the educational advantages required to perform at $\mathrm{A}$ level. $\mathrm{HEFCE}$ statistics ${ }^{4}$ clearly show that pupils from private education perform worse than those from state schools when at university-an example of what might be termed "artificial intelligence." McManus digs further down into his self-made hole in this observation piece saying what he meant was students should be chosen on 
aptitude not on social class, Garlick and Brown have clearly shown their intake have the aptitude to perform at medical school, they just didn't have the A level results.

The message I took from Garlick and Brown's paper is that prospective medical students should be chosen on the basis of actual intellectual ability, not just on A level results, and that students with less good $A$ level results can perform just as well as the highly polished scions of the private school system. What we require are students with the most intelligence (real, not artificial), who are the most suitable to become future medical practitioners.

Paul W Dimmock dimmockpaul@mac.com

Competing interests: PWD is of working class (bog standard comprehensive school) origins yet has still managed to scrape together enough intellectual ability to publish a few BM/papers.

1 Coombes R. BMJ in "smug docs" storm. BMJ 2008;336:1340-1. (14 June.)

2 Garlick PB, Brown G. Widening participation in medicine. BMJ 2008;336:1111-3. (14 June.)

3 Ip H, McManus IC. Increasing diversity among clinicians. BMJ 2008;336:1082-3.

4 Higher Education Funding Council for England. Schooling effects on higher education achievement. Bristol: HEFCE July 2003/32 issue paper.

\section{NICE ON LIPID MODIFICATION}

\section{NICE's simplified approach can't not work}

Laurie writes that a proportion of patients started on simvastatin $40 \mathrm{mg}$ for secondary prevention will not achieve total and low density lipoprotein cholesterols of less than 4 $\mathrm{mmol} / \mathrm{l}$ and $2 \mathrm{mmol} / \mathrm{l}$, respectively. ${ }^{1} \mathrm{He}$ is quite right: even in the trials of the most aggressive statin treatment, about half of patients do not reach these levels, a point emphasised by the National Institute for Health and Clinical Excellence (NICE) in its recent guideline. ${ }^{2}$

Laurie suggests starting with an alternative statin in patients with baseline cholesterol measurements above a threshold derived from the point at which the average reduction achieved with simvastatin $40 \mathrm{mg}$ will not reach the 4 and 2 levels. ${ }^{12}$ Unfortunately this misses several vital points. Firstly, cholesterol levels can vary, as NICE notes, and thus the point estimate on today's test may not be correct. Secondly, the $37 \%$ reduction is an average, not an absolute, for every patient, so individual responses may achieve different reductions. Thirdly, atorvastatin is not licensed to start at $40 \mathrm{mg},{ }^{3}$ and as a result he could be personally liable for any adverse effects that occurred to the patients he decides to treat in this manner. Fourthly, for each patient in whom optimisation of treatment takes slightly longer there may be several who suffer adverse effects due to these clinical short cuts. These patients often decline any further treatment out of fear and remain suboptimally treated forever: an opportunity cost seemingly uncounted.

For the reason already mentioned, NICE makes it clear that levels 4 and 2 are not a treatment goal for all patients and that titration from simvastatin $40 \mathrm{mg}$ should stop at the $80 \mathrm{mg}$ dose as progressing beyond this in stable secondary prevention patients is simply not cost effective (and as other respondents have noted there is debate about whether it is even clinically effective in this group ${ }^{4}$ ). Thus the point about starting with atorvastatin at whatever dose is irrelevant: it shouldn't be used in this circumstance. It then follows that there is also no need for the extra tests and clinician time he laments.

It seems this approach will work after all. Magnus I Hird pharmacist practitioner, Bloomfield Medical Centre, Blackpool FY1 6JW

magnus.hird@blueyonder.co.uk

Competing interests: $\mathrm{MIH}$ is paid by the National Prescribing Centre as a trainer and author, although this response is made personally and may not represent their views. His consultancy provides training and writing to other clients which may include lipid topics.

1 Laurie SJ. NICE's simplified approach to lipids will not work. BMJ 2008;336: 1324. (31 May.)

2 National Institute for Health and Clinical Excellence. Clinical guideline 67: Lipid modification (full guideline). London: NICE, 2008.

3 Electronic Medicines Compendium. Lipitor SPC. http:// emc.medicines.org.uk/

4 Burrill P. Electronic response. bmj.com 2008. http:// bmj.com/cgi/eletters/336/7657/1324\#197081

\section{CLIMATE CHANGE}

\section{Breastfeeding tackles both obesity and climate change}

By enabling more women than currently do so to exclusively breast feed their children for the first six months of life, we could reduce the number of children requiring attention for overweight. ${ }^{1}$ There would be less need for the diversion of foodstuffs through dairy animals to produce breastmilk replacements, and less need for the use of materials and energy to fuel the processes required to modify, package, and distribute animal milk to make it less unsafe for human infants. Breasts do not require scrupulous washing with detergents in hot water between feeds. Families would have more of their income available to purchase better food for their older members, many nations would be less reliant on the import of essential foodstuffs, and population fertility would be reduced when fewer children are weaned from the breast prematurely. The additional solid waste burden resulting from artificial feeding would be nearly eliminated, from agricultural pollution to fewer nappies and pads to absorb menstrual flow, since artificially fed children produce more faeces and urine and their mothers resume menstruation sooner than if they were breast feeding.
The indirect effects of exclusive breast feeding for the first six months and the safe use of adequate weaning foods over the next couple of years would be to reduce the incidence of many conditions currently burdening healthcare systems.

Rachel Myr midwife, Sørlandet sykehus, Kristiansand, Norway rachel@myr.no

Competing interests: None declared.

1 Dobson R. Obesity and climate change could be tackled together. BMJ 2008;336: 1333. (14 June.)

\section{Why so many open windows?}

It is right to encourage doctors to combat climate change. ${ }^{1}$

On 28 February I paid a visit to a local general hospital (500 beds plus) to count the number of open windows in all areas-there were 358. The building is some 30 years old. Most of the original windows were replaced with double glazed ones some years ago. I have difficulty working out how effective the double glazing is when the windows are open.

On Good Friday (21 March) I visited a friend in a surgical block at another hospital-on one face of the block I counted 40 open windows. At yet another hospital on Easter Monday, a particularly chilly day, there were 208 open windows-some were high up in corridors, and I suspect that they had been open for years.

In hospitals there are various lightly clad occupants who may find the ambient temperature oppressive, as may well-clad visitors-so windows get opened. Windows are also opened to clear unpleasant smells. Domestics need to dry off wet mopped surfaces. People who open windows rarely close them-it is no one's job; someone else is paying the heating bill; "fresh air is good for you-and (as with shops with open doors) the system simply belches out more heat, so no one feels cold.

Barrie Smith retired physician, Birmingham hongkongwelshiain@yahoo.co.uk Competing interests: None declared.

1 Godlee F. Climate change: permission to act. Editor's choice. BMJ 2008;336: 0. (26 January.)

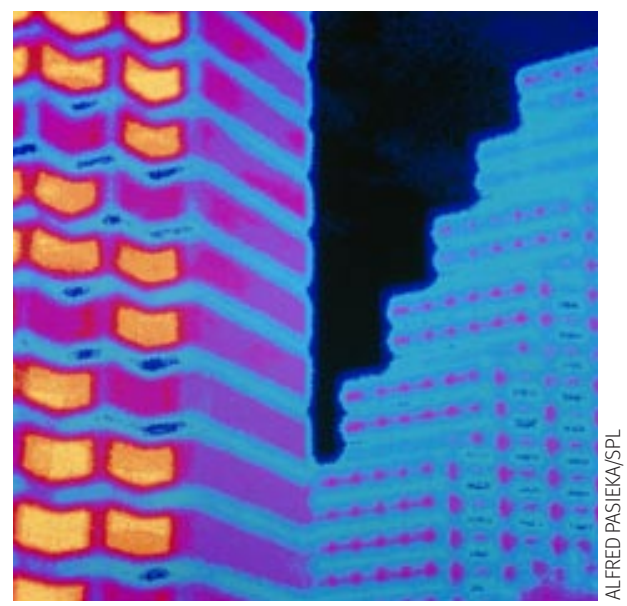

